\title{
CONGENITAL HEMIHYPERTROPHY WITH LYMPHANGIOMA
}

\author{
BY \\ J. ALED WILLIAMS \\ From the Children`s Department, the Caernarvonshire and Anglesey General Hospital, Bangor
}

(Received for Publication february 15, 1950)

Congenital hemihypertrophy is a condition in which the whole of one side of the body is increased in size from birth. In a complete review of the subject Ward and Lerncr (1947) state that more than 100 cases have been described since the first descrip:ion was recorded by Wagner in 1839 .

The incidence of the condition is difficult to assess. Males, according to Gesell (1927), are more ccmmonly affected than females. Hypertrophy has been described in a $10 \mathrm{~mm}$. embryo, but its early recognition depends upon the observer's awareness of the existence of such an entity. In some cases malformation is not noticed until after puberty.

Various theories on the aetiology have been put forward. The hormonal theories, which postulate an abnormal function of the ductless glands, are difficult to reconcile with the one-sided nature of the condition, and in all but one of the post-mortem reports the endocrine glands have been found to be normal. The single exception is that of Hutchison (1915-16), who described enlarged adrenal glands on the involved side.

Rugel (1946) mentions that hemihypertrophy is in some way associated with ' an embryonic defect of the vegetative nervous system, and that the hypertrophy is caused by an excess of the trophic function of the nervous system. Rugel's case revealed hypertrophy of both cerebral hemispheres, but Gesell (1921) describes three cases in which there was an enlargement of the cerebral hemisphere on the same side as the somatic enlargement.

According to Sheldon (1946) generalized dilatation of the lymph spaces of the whole of one side of the body is a cause of hemihypertrophy, and the patchy, bluish appearance of the skin in some of the cases indicates a mixture of naevoid and lymphangiectatic states.

Pressure upon the developing ovum or foetus, or lesions of the central nervous system, would be expected to produce hemiatrophy rather than hemihypertrophy.

Congenital syphilis and neurofibromatosis have also been suggested as causes of hemihypertrophy, but definite evidence is lacking.

Reed (1925) reports the occurrence of hemihypertrophy in a brother and sister, and Scott (1935) its appearance in a mother and daughter. No further evidence of heredity as an aetiological factor is to be found.

\section{Clinical Features}

It is stated by Ward and Lerner (1947) that mental deficiency occurs in about $20^{\circ}$ of these cases, and may often draw attention to the abnormality. Gross asymmetry is usually obvious, and the subcutaneous tissue appears to be thickened. Hair growth is greater, and the pupil is larger, on the affected side of the head. Various postural defects may result from the hypertrophy: Hench, Wakefield, and Camp (1932) describe the development of postural sciatica. The right side of the body is more frequently affected than the left.

More than half the cases show other abnormalities in addition to hypertrophy. Abnormal nail growth, premature eruption of teeth, clubbed feet, congenital heart disease, polydactylism, supernumerary nipples, syndactylism, and excessive secretion of sweat and sebaceous glands, have all been recorded.

\section{Case Report}

A girl, aged 6 years, was brought to the clinic, her mother being anxious to know whether there was any risk attached to the extraction of the child's teeth, which were found to be carious. The patient was an only child, born at full term by breech delivery with forceps on the head. The birth weight was $11 \mathrm{lb}$. $9 \mathrm{oz}$. There was a slight superficial injury to the left side of the neck. It was noticed at birth that the child's right side was larger than her left. The maternal milk supply became inadequate after the third week, and the infant was then fed on National dried milk up to the age of 10 months, when mixed feeding was instituted.

Teething started in the right lower jaw at 4 months, and at 7 months, when teeth first appeared in the left jaw, she had already seven teeth on the right. She sat 


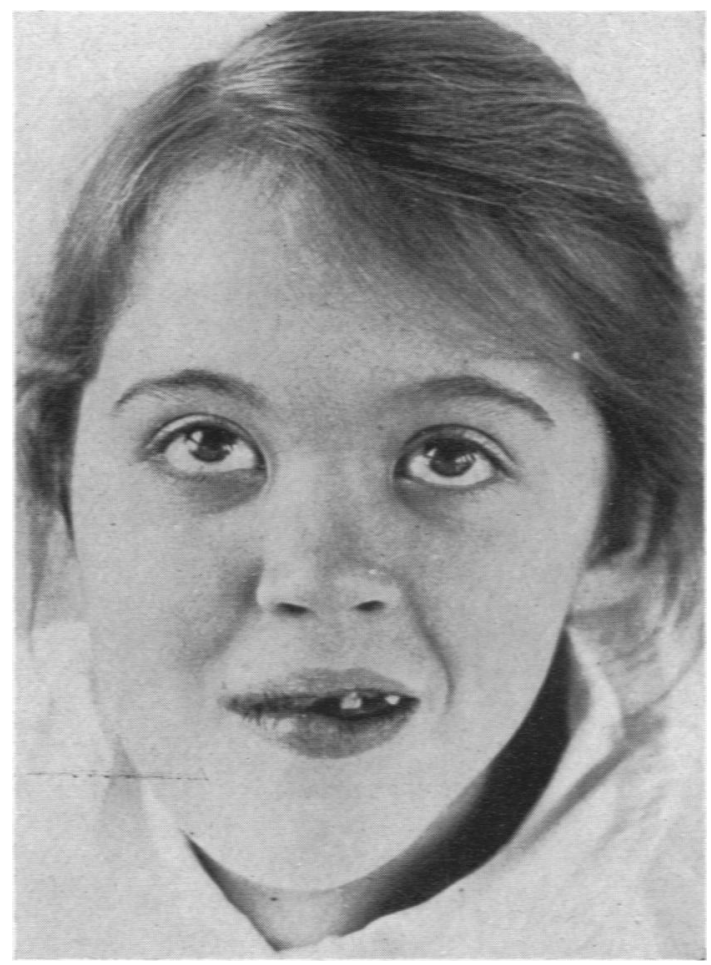

FK. 2.

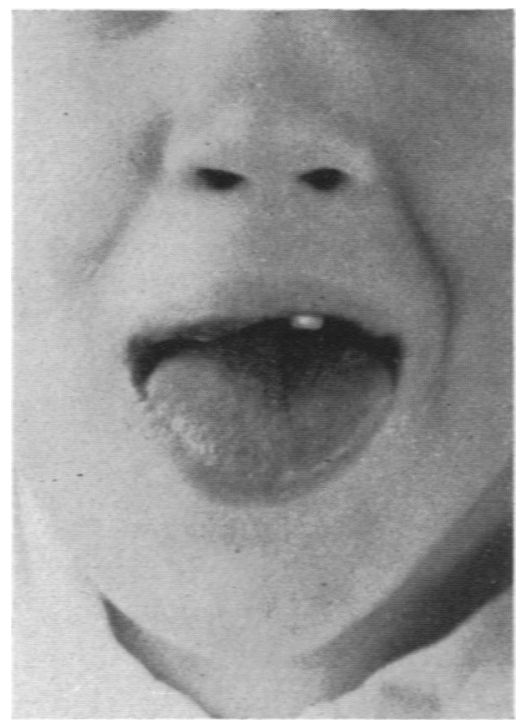

Fig. 3.

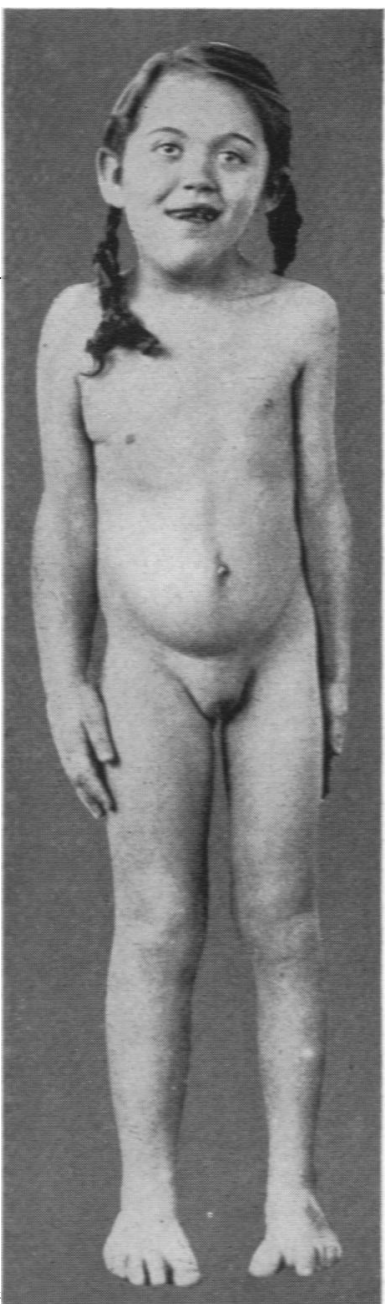

FiG. 1.-Full length photograph to show asymmetry of the body, the face, and the difference in size between right and left limbs, and the cleft between the enlarged left first and second toes.

Fig. 2.-Photograph to show asymmetry of face.

Fig. 3.- Photograph to show enlargement of right half of tongue and hypertrophy of the papillae. 


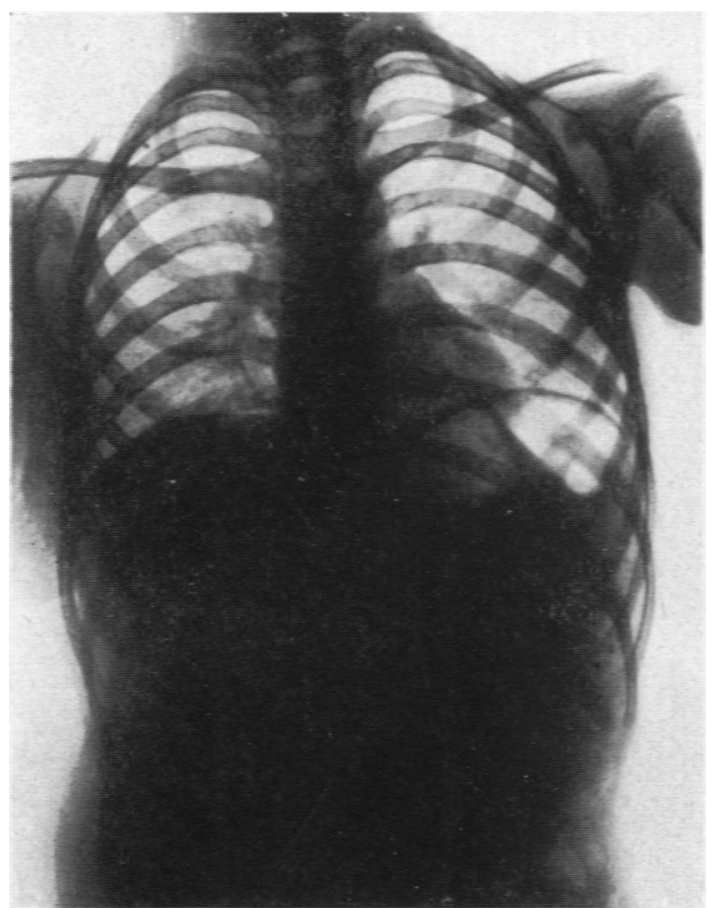

Fig. 4.-Radiograph of chest showing increase in size of soft tissue shadow on the right side.

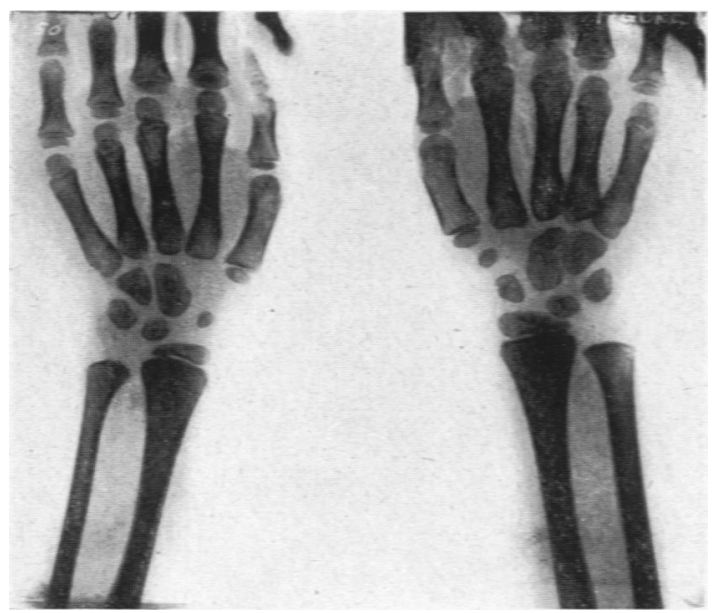

Fig. 5.-Radiograph of right and left writst to show enlargement of right ulna, carpal and metacarpal bones, and the presence of a centre of ossification for the right trapezium. up unsupported at 9 months, and started to walk at 3 years of age. She had whooping cough at the age of 9 months, and measles when 6 years old.

FAMIIY History. Her mother had an uneventful pregnancy, and has always been healthy. Her father has been healthy, and there is no history of abnormality on either side.

Cunnical Examination. A pleasant child, she was of normal height, but one half of her body showed a marked asymmetry. The whole of her right side was enlarged (Fig. 1). This enlargement involved the soft tissues of the face, the tongue, gums, arm, thorax, abdomen, and leg.

It was especially noticed that no change in character could be distinguished between the hair on the right and left sides of the head. The pupils were equal. The left first and second toes showed some hypertrophy of the soft tissues (Fig. 1).

Over the left loin there was a soft, compressible, diffuse, pyriform swelling with its apex at the twelfth dorsal spine, extending down towards the gluteal region. Its inner margin was the midline, and its lower margin the posterior third of the iliac crest.

The child's intelligence was below standard. There was no evidence, however, of a central nervous lesion. Clinical examination showed that the tonsils and pharynx were normal. The primary teeth and the six-year-old molars were all carious. The chest and heart were normal. No mass or organ enlargement was palpable in the abdomen.

INVESTIGATIONS. Haemoglobin was $80 \%$, and red cell count was $4,300,000$ per c.mm. of blood. The white cell count was 6,000 per c.mm. of blood. Bleeding time was 1 minute 30 seconds, and the coagulation time 2 minutes 10 seconds. Urine examination revealed no abnormality. The electrocardiographic records were normal.

A series of radiographs was taken: the skull showed an increase of digital markings, but the pituitary fossa was normal and there was no bony enlargement on the right side.

No bony abnormality appeared in the chest, but the thickness of the soft tissue shadow was markedly increased on the right side (Fig. 4). Radiographs revealed that the right ulna, carpal, and metacarpal bones were larger than those of the left arm. The centre of ossification for the trapezium was present in the right, but absent from the left carpus (Fig. 5).

The leg bones showed no abnormality, but the thickness of the soft tissue shadow of the right leg was considerably greater than that of the left.

Various measurements are given in Tables 1-3.

\section{Discussion}

This case showed a right-sided hemihypertrophy which, with the exception of the right ulna, carpal and metacarpal bones, appeared to involve only the lymphatic elements. The soft compressible nature of the hypertrophy was particularly noticeable. Congenital dilatation of lymph spaces occurs in a localized form, as in cystic hygroma of the neck. In 
TABLE 1

Arm Measurements

\begin{tabular}{|c|c|c|}
\hline & $\begin{array}{l}\text { Right } \\
\text { (in.) }\end{array}$ & $\begin{array}{l}\text { Left } \\
\text { (in.) }\end{array}$ \\
\hline $\begin{array}{l}\text { From acromial angle to external } \\
\text { epicondyle } \\
\text { From acromial angle to tip of radial }\end{array}$ & $8 \frac{1}{2}$ & 8 \\
\hline $\begin{array}{llll}\text { styloid } & \ldots & \ldots & \ldots\end{array}$ & 15 & 14 \\
\hline Circumference of forearm . . & 8 & 6 \\
\hline Circumference of arm $\quad \ldots \quad \ldots$ & 8 & 6 \\
\hline
\end{tabular}

TABLE 2

Leg Measurements

\begin{tabular}{|c|c|c|}
\hline & $\begin{array}{l}\text { Right } \\
\text { (in.) }\end{array}$ & $\begin{array}{c}\text { Left } \\
\text { (in.) }\end{array}$ \\
\hline 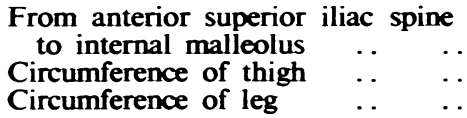 & $\begin{array}{l}23 \frac{1}{2} \\
14 \\
10\end{array}$ & $\begin{array}{c}23 \frac{1}{2} \\
13 \\
9\end{array}$ \\
\hline
\end{tabular}

TABLE 3

Miscellaneous Measurements

Total height

Circumference of chest at nipple line in inspiration $\quad \cdots \quad \ldots \quad \ldots \quad \ldots$

Right chest (measured from mid-line anteriorly to midline posteriorly)

Left chest (measured from mid-line posteriorly to mid-line anteriorly)

23 ,,

11, a generalized form it occurs as lymphangiectasis, involving one or more limbs or the tongue. The interest of this particular case lay in the exhibition of a complete hemi-lymphangiectasis, including hemi-macroglossia (Fig. 3), associated with a large lymphangioma on the back.

Another point of interest was whether the bones of the right hand were merely larger than those on the left, or whether the bone age was slightly advanced on the right. It is noteworthy that with the exception of the left first and second toes, the hypertrophy was confined to the right side.

\section{Summary}

A case of hemihypertrophy is reported in a girl of 6 years, with notes on theories of aetiology and clinical features.

My thanks are due to Dr. Gwyn Griffith, under whose care the child was admitted, and to Mr. Hammond for the photographs.

\section{REFERENCES}

Gesell, A. (1921). Arch. Neurol. Psychiat., Chicago, 6, 400 .

(1927). Amer. J. med. Sci., 173, 542.

Hench, P. S., Wakefield, E. G., and Camp, J. D. (1932). Med. Clin. N. Amer., 15, 1497.

Hutchison, R. (1915-16). Proc. roy. Soc. Med., 9. Sect. Stud. Dis. Child., p. 66

Reed, E. A. (1925). Arch. Neurol. Psychiat., Chicago, 14,824

$12 \frac{1}{2}$, Scott, A. J. (1935). J. Pediat., 6, 650.

Sheldon, W. (1946). "Diseases of Infancy and Childhood,' 5th ed., p. 474. London.

Ward, J., and Lerner, H. H. (1947). J. Pediat., 31, 403. 